Original Article

\title{
Effect of two different kinesio taping techniques on knee kinematics and kinetics in young females
}

\author{
Senem Guner, PT, PhD ${ }^{1)^{*}}$, Serap AlsancaK ${ }^{1)}$, Mitat Koz ${ }^{2)}$ \\ 1) Department of Orthopedic Prosthetics and Orthotics, Vocational School of Health Services, Ankara \\ University: Fatih Caddesi 197/A, 06290 Keçioren, Ankara, Turkey \\ 2) Sports Sciences Faculty, Ankara University, Turkey
}

\begin{abstract}
Purpose] The application of kinesio taping may improve strength and performance, inhibit and facilitate motor activity, and increase range of motion. The aim of this study was to compare the effects of kinesio taping facilitation and inhibition applications on spatiotemporal knee kinematics and kinetics during walking activity in healthy subjects. [Subjects and Methods] A three-dimensional quantitative gait evaluation was performed without tape and with, facilitation and inhibition kinesio taping application on the knee. Sixteen healthy female college students (age, $19.7 \pm 0.4$ years; height, $1.64 \pm 3.4 \mathrm{~cm}$; body mass, $51.5 \pm 4.8 \mathrm{~kg}$ ) participated in the study. [Results] Spatiotemporal parameters (cadence, walking speed, stride length) were significantly different among the trials. Knee joint sagittal plane range of motion was not different with either kinesio taping application. Knee external flexion moment during the early stance phase decreased significantly with facilitation kinesio taping and increased with the inhibition kinesio taping. Knee external extension moment during the mid-stance phase increased with facilitation kinesio taping. Knee power parameters, eccentric activity in the rectus femoris during the pre-swing phase was significantly increased with inhibition kinesio taping application, while eccentric activity of the hamstrings during the terminal swing of gait was decreased. [Conclusion] These findings showed that facilitation kinesio taping application affected the terminal stance phase and that inhibition kinesio taping influenced the terminal swing phase compared with the no tape condition.

Key words: Kinesio tape, Knee joint, Gait analysis
\end{abstract}

(This article was submitted Jun. 5, 2015, and was accepted Jul. 6, 2015)

\section{INTRODUCTION}

Kinesio taping (KT) is an alternative taping technique developed in the 1970 s by Dr. Kenzo Kase. According to Kase, KT may improve strength, control, and performance; reduce pain; prevent injury; inhibit and facilitate motor activity; and increase range of motion (ROM $)^{1-3)}$. KT has lately gained popularity among sports professionals for injury prevention and performance enhancement ${ }^{4}$. However, the mechanism through which KT exerts its hypothesized effects is unclear, and studies have not confirmed on the effectiveness of the methodology. KT has been shown to support muscle movement and relieve abnormal feeling or pain in the skin. Mori et al. ${ }^{5)}$ suggested KT normalizes muscle function, and Kase et al. ${ }^{2)}$ showed that the stretch rate and width of the KT affects the fascia and flow of lymph fluid. KT also reduces cervical pain and increases ROM 24 hours after whiplash injury6), and according to Slupik et al. ${ }^{7}$, it has a preliminary effect on quadriceps peak torque and electromyographic activity in

*Corresponding author. Senem Guner (E-mail: sguner@ ankara.edu.tr)

C2015 The Society of Physical Therapy Science. Published by IPEC Inc. This is an open-access article distributed under the terms of the Creative Commons Attribution Non-Commercial No Derivatives (by-ncnd) License $<$ http://creativecommons.org/licenses/by-nc-nd/3.0/>. healthy subjects. Chang et al. found no significant difference in maximal wrist flexor strength among 10 baseball players who received KT, a placebo, or no tape ${ }^{8)}$. Only a study by Lee et al. has reported a positive acute effect of KT on isometric muscle strength ${ }^{9)}$.

Although KT is widely used in clinical practice, several studies show no any change in muscle strength with KT application in healthy individuals ${ }^{10-12}$. A few research studies have evaluated the biomechanical effectiveness of KT during walking or running. Howe et al. showed that KT does not change hip or knee kinematics or kinetics in asymptomatic runners compared with the no tape condition ${ }^{13)}$. Wong et al. indicate that KT does not alter the muscle peak torque generation or total work done in healthy subjects ${ }^{14)}$. The current investigation compared the effects of KT facilitation and inhibition applications on spatiotemporal knee kinematics and kinetics during walking.

\section{SUBJECTS AND METHODS}

Sixteen healthy female college students from Ankara University volunteered for this study. All subjects were completely inactive. Those who reported active knee pain; lower limb trauma; a history of spinal, hip, knee, or foot pathology; or any neurological impairment were excluded. Average age, body weight, and height were $19.7 \pm 0.4$ years old, $51.5 \pm$ $4.8 \mathrm{~kg}$, and $1.64 \pm 3.4 \mathrm{~cm}$, respectively. All participants 
provided informed consent, and the study was approved by the Orthopedic Prosthetic and Orthotic Department Review Board Commission of the University of Ankara.

The Kinesio tape was a hypoallergenic, nonmedicated, waterproof, porous, adhesive tape made of cotton that could be stretched longitudinally up to $30-40 \%$ of its original length. The subject's skin was shaved, cleaned with alcohol, and dried before the tape was applied.

Facilitation $K T^{2)}$ (Fig. 1): Y-shaped KT was applied the quadriceps of each subject, according to Kenso Kase's Kinesio taping manual, by the same physical therapist. The two extremities of the subject's knees were taped while the subject lay in the supine position with the hip flexed 30 degrees and the knee flexed 60 degrees. The tape was applied with no tension approximately $5 \mathrm{~cm}$ below the origin of the rectus femoris and with moderate tension $(25-50 \%$ of available tension) along the two tails. The tails were placed on the skin without tension when they were approximately $2-5 \mathrm{~cm}$ from the end. The remaining tape around the patella was unstretched.

Inhibition $K T^{2)}$ (Fig. 2): KT was applied from muscle insertion to origin using light tension (15-25\% of available tension). The tape was a Y-shaped strip, with the tail that surrounded the quadriceps muscle held in the stretching position.

A three-dimensional quantitative gait evaluation was performed in the Motion Analysis Laboratory at the Ankara University Department of Prosthetics and Orthotics using a Vicon Nexus system (Oxford Metrics, Oxford, UK) by the same experienced physiotherapist (SG) using six infrared JAI cameras at $250 \mathrm{~Hz}$ and one force plate (AMTI). The standard plug-in gait marker set was used to capture kinematic data: a total of 16 reflective markers were placed on the anterior superior iliac spine, mid-lateral thigh, lateral knee joint, lateral shank, lateral malleolus, and second metatarsal head, over the posterior calcaneus bilaterally, and on the posterior superior iliac spine. Force plates were embedded in the middle of a $10 \mathrm{~m}$ walkway. The cameras and force plate were calibrated before data collection. Subjects were asked to walk barefoot at a comfortable, self-selected walking speed without tape and then application of facilitation and inhibition KT, respectively. At least five good trials in which the subject's footfalls landed completely on the force plates were captured.

Descriptive statistics were calculated for all data. Statistical analyses were performed using the SPSS version 16 software. Statistical analyses of the data were performed by a blinded assessor. The nonparametric Wilcoxon test was used to compare baseline measurements and measurements for the two taping applications, respectively, within each subject. The statistical significance level was set at $\mathrm{p}<0.05$.

\section{RESULTS}

Spatiotemporal parameters were significantly different among the trials (Table 1). Cadence walking speed and stride length increased with the facilitation KT application compared with the no tape condition $(\mathrm{p}<0.05)$. Cadences significantly increased and stride length decreased with the

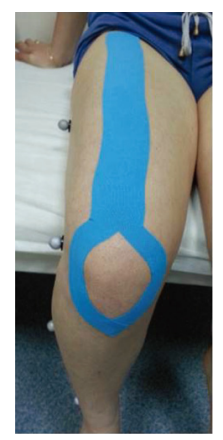

Fig. 1. Facilitation application

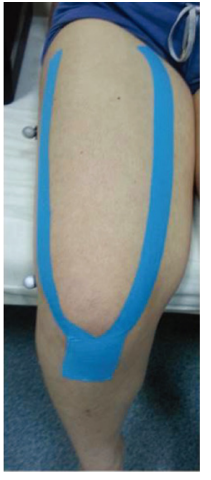

Fig. 2. Inhibitation application

inhibition KT application compared with the no tape condition $(\mathrm{p}<0.05)$.

Kinematic data are displayed in Table 2. Sagittal plane knee joint kinematics were significantly different with both KT applications, respectively, compared with the no tape condition. The degree of maximal knee flexion was significantly lower with the inhibition KT application, and degree of maximum knee extension was significantly increased with both KT applications compared with the no tape condition. Knee joint sagittal plane ROM was not different with either KT application.

Kinetic data are displayed in Table 3. Knee external flexion moment during the early stance phase (KM1) decreased significantly with the facilitation KT $(\mathrm{p}<0.05)$ and increased with the inhibition KT $(\mathrm{p}<0.05)$. Knee external extension moment during mid-stance phase (KM2) increased with the facilitation KT $(\mathrm{p}<0.05)$. Knee power parameters, including eccentric knee extensor activity during loading response (i.e., eccentric quadriceps activity, KP1) and concentric knee extensor activity during mid-stance (i.e., concentric quadriceps activity, KP2) were not significantly different after either KT application. Eccentric activity in the rectus femoris during the pre-swing phase (KP3) was significantly increased with the inhibition KT application $(\mathrm{p}<0.05)$, while eccentric activity of the hamstrings during the terminal swing of gait $(\mathrm{KP} 4)$ was decreased $(\mathrm{p}<0.05)$.

\section{DISCUSSION}

The main purpose of the current study was to determine whether KT had short-term effects on knee kinematics and kinetics parameters using two different $\mathrm{KT}$ techniques in the knees of healthy individuals. Our study showed significant differences in spatiotemporal parameters, knee kinematics, and kinetics gait analysis parameters with facilitation and inhibition KT applications.

Facilitation KT application enhanced cadence, stride length, walking speed, and the degree of maximal knee extension compared with the no-tape condition. This application also increased knee extensor moment, which suggests increased quadriceps muscle torque generation, and decreased knee flexor moment. Increased cadence may explain the increased knee extensor moment. An elevation 
Table 1. Spatiotemporal parameters

\begin{tabular}{|c|c|c|c|}
\hline & $\begin{array}{c}\text { No tape } \\
\mathrm{n}=16\end{array}$ & $\begin{array}{c}\text { Facilitation } \\
\text { KT } \\
n=16\end{array}$ & $\begin{array}{c}\text { Inhibition } \\
\text { KT } \\
\mathrm{n}=16\end{array}$ \\
\hline Cadence (steps/min) & $110 \pm 7.4$ & $113 \pm 7.4^{* *}$ & $115 \pm 8.5^{*}$ \\
\hline Stride length $(\mathrm{m})$ & $1.29 \pm 0.07$ & $1.30 \pm 0.06^{*}$ & $1.27 \pm 0.07^{*}$ \\
\hline Walking speed $(\mathrm{m} / \mathrm{s})$ & $1.20 \pm 0.8$ & $1.23 \pm 0.5^{*}$ & $1.21 \pm 0.8$ \\
\hline \multicolumn{4}{|c|}{$\begin{array}{l}\text { ** } \mathrm{p}<0.001 ; * \mathrm{p}<0.05 \\
\text { Comparison of the no tape condition, facilitation KT, and inhibi- } \\
\text { tion KT by nonparametric Wilcoxon test } \\
\text { Cadence: The number of steps per minute. } \\
\text { Step length: The distance along the line of progression from op- } \\
\text { posite foot contact to current foot contact. } \\
\text { Walking speed: The speed of the current foot based on the stride } \\
\text { time and stride length. }\end{array}$} \\
\hline
\end{tabular}

Table 2. Sagittal plane joint angles (degrees)

\begin{tabular}{lccc}
\hline $\begin{array}{l}\text { Kinematic parameters } \\
\text { Sagittal plane }\end{array}$ & $\begin{array}{c}\text { No tape } \\
\mathrm{n}=16\end{array}$ & $\begin{array}{c}\text { Facilitation } \\
\mathrm{KT} \\
\mathrm{n}=16\end{array}$ & $\begin{array}{c}\text { Inhibition } \\
\mathrm{KT} \\
\mathrm{n}=16\end{array}$ \\
\hline $\begin{array}{l}\text { Knee flexion- } \\
\text { extension ROM }\left(^{\circ}\right)\end{array}$ & $60.7 \pm 3.4$ & $61.2 \pm 3.8$ & $60.4 \pm 3.9$ \\
$\begin{array}{l}\text { Max knee flexion }\left({ }^{\circ}\right) \\
\text { Max knee extension }\left({ }^{\circ}\right)\end{array}$ & $-37.1 \pm 2.9 \pm 3.3$ & $-3.8 \pm 4.1^{*}$ & $-3.6 \pm 4.0^{*}$ \\
\hline$* * \mathrm{p}<0.001 ;{ }^{*}<0.05$ \\
$\begin{array}{l}\text { Comparison of the no tape condition, facilitation KT, and inhibi- } \\
\text { tion KT by nonparametric Wilcoxon test }\end{array}$
\end{tabular}

Table 3. Sagittal plane moments $(\mathrm{Nm} / \mathrm{kg})$ and powers (W)

\begin{tabular}{lccc}
\hline $\begin{array}{l}\text { Kinetic } \\
\text { parameters } \\
\text { Sagittal plane }\end{array}$ & $\begin{array}{c}\text { No tape } \\
\mathrm{n}=16\end{array}$ & $\begin{array}{c}\text { Facilitation KT } \\
\mathrm{n}=16\end{array}$ & $\begin{array}{c}\text { Inhibition KT } \\
\mathrm{n}=16\end{array}$ \\
\hline KM1 & $0.21 \pm 0.1$ & $0.15 \pm 0.11^{*}$ & $0.31 \pm 0.0^{*}$ \\
KM2 & $-0.26 \pm 0.16$ & $-0.32 \pm 0.15^{*}$ & $-0.07 \pm 0.2$ \\
KP1 & $-0.24 \pm 0.2$ & $-0.31 \pm 0.3$ & $-0.27 \pm 0.2$ \\
KP2 & $0.13 \pm 0.1$ & $0.10 \pm 0.7$ & $0.03 \pm 0.07$ \\
KP3 & $0.15 \pm 0.13$ & $0.19 \pm 0.2$ & $0.19 \pm 0.1^{*}$ \\
KP4 & $-1.47 \pm 0.57$ & $-1.45 \pm 0.5$ & $-0.74 \pm 1.1^{*}$ \\
\hline
\end{tabular}

$* * \mathrm{p}<0.001 ; * \mathrm{p}<0.05$

Comparison of the no tape condition, facilitation KT, and inhibition KT by nonparametric Wilcoxon test

KM1: maximum knee flexion moment; KM2: maximum knee extension moment;

KP1: eccentric knee extensor activity during the loading response phase; KP2: concentric knee extensor activity during the mid-stance phase; KP3: eccentric activity in the rectus femoris during the pre-swing phase; KP4: eccentric activity in the hamstrings during terminal swing

in the quadriceps lever arm in the taped condition may have augmented knee extensor moment without increasing quadriceps muscle force. A meta-analysis by Williams et al. ${ }^{4}$ indicates that seven out of ten studies they examined showed an increase in muscle strength with KT application; however, three isokinetic studies did not show a significant effect of KT application on quadriceps muscle strength in healthy subjects. According to Lumbroso et al. ${ }^{15)}$, application of KT to the gastrocnemius increased the muscle's peak force immediately and after application of KT for 2 days, and ROM increased in all of the lower-extremity joints measured.

KT may increase blood circulation within the taped area, which may influence the muscle and myofascial functions that increase ROM within the muscle ${ }^{16)}$. KT application may stretch or increase pressure applied to the skin, and this external load may stimulate cutaneous mechanoreceptors that impact knee flexion/extension ROM. The mechanical load on muscle from the taping may also increase muscle excitability. Another possibility is that fear of movement is related to pain intensity in patients and that application of KT provides sensory feedback that increases $\mathrm{ROM}^{6}$ ). $\mathrm{KT}$ is used to correct biomechanical movements, allowing individuals to improve performance by increasing the power created through their movements. Hsu et al. showed that KT significantly improved scapular orientations compared with a placebo treatment in baseball players with shoulder impingement syndrome ${ }^{17}$ ). Slupik et al. showed a $54 \%$ increase in vastus medialis muscle activity 24 hours after KT application ${ }^{7)}$. Karatas et al. reported that KT may be an effective method for reducing neck and low back pain and improving functional performance ${ }^{18)}$. In a study of 40 asymptomatic trained amateur cyclists, Nelson found that KT application above the rectus femoris significantly increased knee flexion ${ }^{19}$ ). Yeung et al. suggested that KT shortens the time to reach peak torque generation during isometric knee extension, which has important implications for sports performances that require the rapid generation of peak muscular force $^{20)}$. Our results demonstrated that facilitation KT application improved gait performance by increasing cadence, walking speed, and knee extension moment.

Research has shown that application of KT to healthy tennis players decreased fatigue by maintaining forearm extensor strength ${ }^{21)}$, and this suggests that KT may have also affected proprioception in addition to improving muscular strength and power in present study. However, other studies have shown that KT did not improve proprioceptive response in the ankle, as determined by reproductive measures of joint position sense ${ }^{1}$. The proprioceptive effect of $\mathrm{KT}$ is unclear, but KT may stimulate the cutaneous mechanoreceptors by applying pressure to, and stretching, the skin; thus, an elastic tape such as Kinesio tape may cause proprioceptive stimulation while improving joint ROM and muscle function, further enhancing cadence ${ }^{22}$ ). Our results suggest that facilitation KT application may enhance an individual's gait performance during walking or sportive activities due to its assistance of the terminal stance in the gait cycle. Therefore, KT application may facilitate walking or gait activity and reduce fatigue.

The inhibition KT technique increased knee flexor moment, decreased knee power (i.e., eccentric activity of the hamstrings) during the terminal swing phase, and decreased knee flexion during walking. However, the mechanism behind this KT application technique is largely unknown. Slupik et al. suggest that the inhibition KT application increases motor unit recruitment in asymptomatic individuals several hours after KT is applied, which would justify the lack of biomechanical changes resulting from this method of KT. 
Runners often use KT to manage overuse injuries. We propose that the inhibition KT application technique improves minor soft tissue injury recovery and prevents overuse injuries in the joint of interest. Inhibition KT application had a positive effect on knee kinetics and kinematics compared with the no-tape condition in our study. Inhibition KT application with physical therapy rehabilitation treatment in the acute phase or with orthotic treatment may be valuable, and it may also help control knee hyperextension in paralytic patients with knee-ankle foot orthosis (KAFO) without the need for orthotic popliteal straps. Also, patients with equinus have prevalent knee hyperextension and may benefit from inhibition KT application along with ankle-foot orthosis (AFO).

There were several limitations in this study. First, the study had small sample sizes, which may limit the translatability of our findings to other populations. Second, placebo effects may have contributed to the observed differences because we did not apply placebo taping to eliminate the psychological effect of the tape. Further research is recommended to examine the association between sports performance with therapeutic tape and the acute and chronic effects of KT on the function, balance, and neuromuscular performance of patients under a rehabilitation program.

\section{ACKNOWLEDGEMENT}

The authors declare that they received no financial assistance for the present project.

\section{REFERENCES}

1) Halseth T, McChesney JW, Debeliso M, et al.: The effects of kinesio ${ }^{\mathrm{TM}}$ taping on proprioception at the ankle. J Sports Sci Med, 2004, 3: 1-7. [Medline]

2) Kase K, Wallis J, Kase T: Clinical Therapeutic Applications of the Kinesio Taping Method, 2nd ed. Tokyo: Ken Ikai, 2003, pp 10-20.

3) Murray H, Husk LJ: Effect of Kinesio Taping on proprioception in the ankle. J Orthop Sports Phys Ther, 2001, 31: A-37.

4) Williams S, Whatman C, Hume PA, et al.: Kinesio taping in treatment and prevention of sports injuries: a meta-analysis of the evidence for its effectiveness. Sports Med, 2012, 42: 153-164. [Medline] [CrossRef]

5) Mori S: How Kinesio taping method can induce effectiveness for treatment of scapular arch. 16th Annual Kinesio Taping International Symposium Review, 2001, pp 50-53 [in Japanese].
6) González-Iglesias J, Fernández-de-Las-Peñas C, Cleland JA, et al.: Shortterm effects of cervical kinesio taping on pain and cervical range of motion in patients with acute whiplash injury: a randomized clinical trial. J Orthop Sports Phys Ther, 2009, 39: 515-521. [Medline] [CrossRef]

7) Słupik A, Dwornik M, Białoszewski D, et al.: Effect of Kinesio Taping on bioelectrical activity of vastus medialis muscle. Preliminary report. Ortop Traumatol Rehabil, 2007, 9: 644-651. [Medline]

8) Chang HY, Wang CH, Chou KY, et al.: Could forearm Kinesio Taping improve strength, force sense, and pain in baseball pitchers with medial epicondylitis? Clin J Sport Med, 2012, 22: 327-333. [Medline] [CrossRef]

9) Lee JH, Yoo WG, Lee KS: Effects of head-neck rotation and Kinesio taping of the flexor muscles on dominant hand grip strenght. J Phys Ther Sci, 2010, 22: 285-289. [CrossRef]

10) Fu TC, Wong AM, Pei YC, et al.: Effect of Kinesio taping on muscle strength in athletes - a pilot study. J Sci Med Sport, 2008, 11: 198-201. [Medline] [CrossRef]

11) Lins CA, Neto FL, Amorim AB, et al.: Kinesio Taping $\left({ }^{\circledR}\right)$ does not alter neuromuscular performance of femoral quadriceps or lower limb function in healthy subjects: randomized, blind, controlled, clinical trial. Man Ther, 2013, 18: 41-45. [Medline] [CrossRef]

12) Vercelli $S$, Sartorio F, Foti $C$, et al.: Immediate effects of kinesiotaping on quadriceps muscle strength: a single-blind, placebo-controlled crossover trial. Clin J Sport Med, 2012, 22: 319-326. [Medline] [CrossRef]

13) Howe A, Campbell A, Ng L, et al.: Effects of two different knee tape procedures on lower-limb kinematics and kinetics in recreational runners. Scand J Med Sci Sports, 2015, 25: 517-524. [Medline] [CrossRef]

14) Wong OM, Cheung RT, Li RC: Isokinetic knee function in healthy subjects with and without Kinesio taping. Phys Ther Sport, 2012, 13: 255-258. [Medline] [CrossRef]

15) Lumbroso D, Ziv E, Vered E, et al.: The effect of kinesio tape application on hamstring and gastrocnemius muscles in healthy young adults. J Bodyw Mov Ther, 2014, 18: 130-138. [Medline] [CrossRef]

16) Yoshida A, Kahanov L: The effect of kinesio taping on lower trunk range of motions. Res Sports Med, 2007, 15: 103-112. [Medline] [CrossRef]

17) Hsu YH, Chen WY, Lin HC, et al.: The effects of taping on scapular kinematics and muscle performance in baseball players with shoulder impingement syndrome. J Electromyogr Kinesiol, 2009, 19: 1092-1099. [Medline] [CrossRef]

18) Karataș N, Bıcıcı S, Baltacı G, et al.: The effect of Kinesiotape application on functional performance in surgeons who have musculo-skeletal pain after performing surgery. Turk Neurosurg, 2012, 22: 83-89. [Medline]

19) Nelson DK: The effect of kinesio tape on quadriceps muscle power output, length/tension and hip and knee range of motion in asymptomatic cyclists. Durban University of Technology, Durban, 2011.

20) Yeung SS, Yeung EW, Sakunkaruna Y, et al.: Acute effects of kinesio taping on knee extensor peak torque and electromyographic activity after exhaustive isometric knee extension in healthy young adults. Clin J Sport Med, 2015, 25: 284-290. [Medline] [CrossRef]

21) Schneider M, Rhea M, Bay $C$ : The effect of kinesio tex tape on muscular strength of the forearm extensors on collegiate tenisathletes. http://www. kinesiotaping.com $/ \mathrm{kta} /$ researchstudies.html (Accessed Jan. 13, 2011)

22) Murray H: Effects of Kinesio Taping on muscle strength after ACL-repair. J Orthop Sports Phys Ther, 2000, 30: 1. 